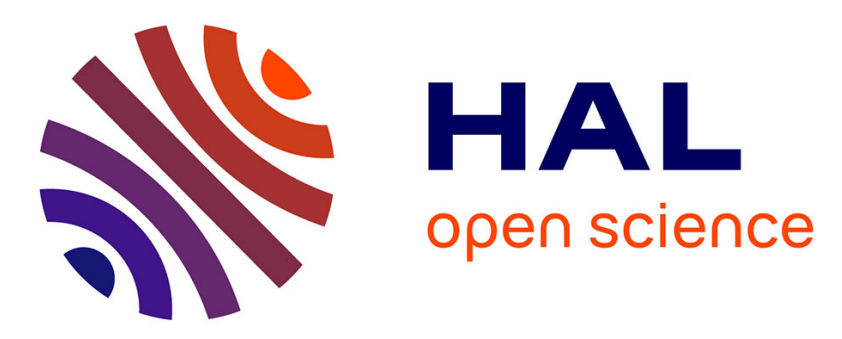

\title{
The shouted voice: a pilot study of the larynx physiology under extreme aerodynamic pressures
}

Aude Lagier, Thierry Legou, Camille Galand, Benoît Amy de La Brétèque, Yohann Meynadier, Antoine Giovanni

\section{- To cite this version:}

Aude Lagier, Thierry Legou, Camille Galand, Benoît Amy de La Brétèque, Yohann Meynadier, et al. The shouted voice: a pilot study of the larynx physiology under extreme aerodynamic pressures. Logopedics Phoniatrics Vocology, 2017, 42 (4), pp.141-145. 10.1080/14015439.2016.1211735 . hal01460046

\section{HAL Id: hal-01460046 \\ https://hal.science/hal-01460046}

Submitted on 30 Sep 2017

HAL is a multi-disciplinary open access archive for the deposit and dissemination of scientific research documents, whether they are published or not. The documents may come from teaching and research institutions in France or abroad, or from public or private research centers.
L'archive ouverte pluridisciplinaire HAL, est destinée au dépôt et à la diffusion de documents scientifiques de niveau recherche, publiés ou non, émanant des établissements d'enseignement et de recherche français ou étrangers, des laboratoires publics ou privés. 
Logopedics Phoniatrics Vocology, 42(4): 141-145.

Pubished online: 2016-08-02 | RoMEO green journal.

DOI: $10.1080 / 14015439.2016 .1211735$

The shouted voice: a pilot study of laryngeal physiology under extreme aerodynamic pressure

Aude Lagier $^{\mathrm{a}, \mathrm{b}}$, Thierry Legou ${ }^{\mathrm{b}}$, Camille Galand ${ }^{\mathrm{b}, \mathrm{c}}$, Benoit Amy de la Brétèque ${ }^{\mathrm{b}, \mathrm{c}}$, Yohann Meynadier $^{\mathrm{b}}$, Antoine Giovanni ${ }^{\mathrm{b}, \mathrm{c}}$

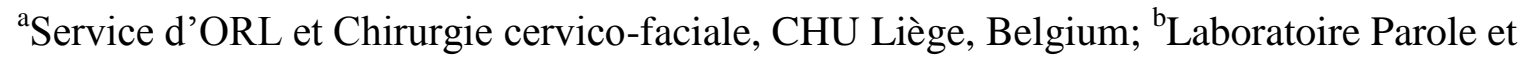
Langage, UMR 7309, CNRS-AMU, France; ' Service d'ORL et Chirurgie cervico-faciale, CHU Timone, AP-HM, Marseille, France

Short title: Shouted voice and aerodynamics

Abstract:

Introduction: The objective was to study the behavior of the larynx during shouted voice production, when the larynx is exposed to extremely high subglottic pressure.

Materials and methods: The study involved electroglottographic, acoustic and aerodynamic analyses of shouts produced at maximum effort by three male participants.

Results and discussion: Under a normal speaking voice, the voice sound pressure level (SPL) is proportional to the subglottic pressure. However, when the subglottic pressure reached high levels, the voice SPL reached a maximum value and then decreased as subglottic pressure increased further. Furthermore, the electroglottographic signal sometimes lost its periodicity during the shout, suggesting irregular vocal fold vibration.

Key-words: subglottic pressure, shout, shouted voice, electroglottography, laryngeal physiology. 
Introduction

A shout is a sudden loud outburst, a very specific form of communication motivated by an emotional or situational context. The speaker seeks to convey an emotion (joy, fear, pain, disgust, anger, excitement) or to warn of danger or of emergency (1). Whatever the motivation behind a shout, it differs greatly in character from the speaker's conversational voice. In shouts, the voice can convey a universally understandable message of emotion regardless of the intelligible content.

Shouted voice is similar and yet distinguished from loud voice. Both involve an increase in subglottic pressure which amplifies glottal vibration and waveform parameters but loud voice is different because there is no suddenness in its production. Many authors have studied loud voice in the context of vocal effort or singing voice (2-8). The findings of these works show that the following flow glottogram parameters increase along with increasing subglottic pressure: the closed quotient, the maximum flow declination rate, the peak-to-peak pulse amplitude, and the speed quotient (8).

In contrast to loud voice, little research has been done on shouts. Shouted speech and the concomitant behavior of the glottal source were studied in healthy volunteers by Mittal and Yegnanarayana in 2013 (1). The objective of their study was to describe shouted speech through the analysis of shouted sentences. They analyzed the voice during the production of vowels in these sentences using electroglottography (EGG) and audio signal analysis. Their report highlighted increases in fundamental frequency and in the closed quotient of the EGG signal. In addition, they observed a change in spectral energy distribution with low-frequency spectral energy decreasing and high frequency spectral energy increasing. Furthermore, the ratio of energy between the low frequencies and the high frequencies was lower for shouted speech than for normally produced speech.

The present study investigates the shouted voice through vowel-like utterances from aerodynamic and vibratory points of view based on electroglottographic and acoustic data.

Materials and methods

\section{Subjects}

Three male subjects aged 37-53 years participated in the study. All were co-authors of the paper. 
Task

The subjects sat in a quiet but not anechoic room (basal noise: $49.2 \mathrm{~dB} \mathrm{C}$ (see below)). They were instructed to "shout a vowel (of their choice) as loud as possible". No instruction was given regarding onset of the shout, frequency, voice SPL or duration target, or ramp up. They all shouted an /a/. In order to preserve spontaneity during the task, shouts were considered valid when the subjects felt they had achieved the target of a very loud shout. The subjects produced multiple shouts until they felt vocal fatigue. Subject 1 performed 6 shouts, subject 2 performed 2 shouts and subject 3 performed 4 shouts, all the shouts were analyzed. The absence of glottal lesion was checked just before and just after the experiment with indirect laryngoscopy.

\section{Voice SPL}

The C-weighted sound pressure level (SPL) was acquired with an AKG C1000S microphone positioned at a distance $90 \mathrm{~cm}$ in front of the subject at head height. The microphone signal was SPL calibrated. The microphone was connected to an EVA2 workstation (Assisted Voice Evaluation 2, SQ Lab, Aix-en-Provence, France), which was used for data storage, post-processing, and analysis. Before the experiment, the microphone and EVA2 workstation were calibrated using a sonometer in an anechoic room at $30 \mathrm{~cm}$ in front of the speaker as classically described (9). The distance between the participant and the microphone was set at $90 \mathrm{~cm}$ in order to avoid saturation of the signal.

The recordings were made at a sampling frequency of $25000 \mathrm{~Hz}$, with no filter. The voice SPL was calculated using the "intensity RMS" function of the Phonedit Signaix ${ }^{\circledR}$ software (Laboratoire Parole et Langage, Aix en Provence). In this software, intensity RMS is the ratio, expressed in decibels, between the RMS pressure of the signal and the reference RMS pressure. The calculation is performed during integration times of $10 \mathrm{msec}$ without overlapping.

Subglottic pressure

Subglottic pressure $\left(\mathrm{P}_{\mathrm{SG}}\right)$ was measured directly by tracheal puncture. A catheter with an inner diameter of $1.3 \mathrm{~mm}$ was perpendicularly inserted between the $1^{\text {st }}$ and $2^{\text {nd }}$ tracheal cartilages in the operating room. No local anesthesia was necessary. The catheter was then maintained with sticking-plaster. The external extremity of the catheter was connected to the pressure sensor of the EVA2® workstation placed $30 \mathrm{~cm}$ away through a flexible tube. 
Subglottic pressure sensor was calibrated on a testbench prior to the experiment. The sampling frequency of the sensor was $6250 \mathrm{~Hz}$. Subglottic pressure was expressed in $\mathrm{kPa}$.

\section{Electroglottography (EGG)}

Electroglottographic signals were collected via a laryngograph (Laryngograph Processor ${ }^{\circledR}$ of Laryngograph ${ }^{\circ}$, London, UK) and recorded simultaneously with the voice SPL and the subglottic pressure using the EVA2® workstation. The sampling frequency was 25.000 Hz. Qualitative analysis of the EGG signal was based on the classification of nonlinear signals proposed by Titze. During some productions, the voice may lose its harmonic characteristics in favor of non-periodic production. Titze proposed a qualitative classification of such vocal signals: Type 1 signals are almost periodic, while type 2 signals are non-periodic with strong modulations or sub-harmonics and type 3 signals are irregular and aperiodic (Titze quoted by Jiang) (10). Their classification was applied here to the EGG signal because it is a physiological correlate of vocal fold vibration, independently of the vocal tract (11). The present study analyzed the periodic signals (type 1), and the nonperiodic signals (type 2 and 3) separately.

The ratio, voice SPL/PSG, was calculated in each periodic and non-periodic segment of each shout at the maximum PSG and using the mean values during the segment.

\section{Results}

Table I summarizes voice SPL, $\mathrm{P}_{\mathrm{SG}}$, and EGG analysis for each shout. The duration of the shout describes the whole shout. Each shout was then segmented using the EGG qualitative analysis into periodic segments and non periodic segments. For each segment, the following measures were calculated: the segment duration as a proportion of the entire shout, the mean $\mathrm{P}_{\mathrm{SG}}$, the mean voice SPL, the maximum $\mathrm{P}_{\mathrm{SG}}$ ( $\mathrm{P}_{\mathrm{SG}}$ max), the ratio of the mean voice $\mathrm{SPL} /$ mean $\mathrm{P}_{\mathrm{SG}}$, and the ratio of the voice SPL/ $\mathrm{P}_{\mathrm{SG}}$ at $\mathrm{P}_{\mathrm{SG}}$ max. The fundamental frequency was not analyzed because, during the non-periodic signals, it was unstable and could not be determined.

Insert table I here, please

Non periodic production episodes, when present, tended to occur at higher $\mathrm{P}_{\mathrm{SG}}$ values than periodic ones. For Subject 1, mean voice SPL was almost the same in non-periodic 
productions as in periodic ones, while for subject 2 it was higher in non-periodic productions. Subject 3 never produced non-periodic signals, although he reached the highest $\mathrm{P}_{\mathrm{SG}}$ in his 4 th shout in which he exceeded the limit of the pressure sensor $\left(\mathrm{P}_{\mathrm{SG}}>\right.$ $20 \mathrm{kPa}$ ). For subjects 1 and 2, the mean voice SPL/ mean $\mathrm{P}_{\mathrm{SG}}$ ratio was always greater during periodic productions than in non-periodic ones (Table I), and voice SPL/ $\mathrm{P}_{\mathrm{SG}} \max$ was almost the same.

Figure 1 shows the relationship between voice SPL and $\mathrm{P}_{\mathrm{SG}}$ for each of the three subjects. A slowdown, or even a decrease, in the curve of intensity exists when $\mathrm{P}_{\mathrm{SG}}$ is close to maximum.

Insert figure 1 here, please

The transition from periodic to non-periodic production typically occurred suddenly from one cycle to the subsequent cycle (Figure 2). This transition was isolated to the EGG and acoustic signals, since it did not affect either the $P_{\mathrm{SG}}$ curves (increasing steadily until doubling), or the voice SPL curves (almost stable)

Insert figure 2 here, please

Discussion

The laryngeal physiology under very high $P_{S G}$

Most researchers who have studied vocal efficiency estimated $\mathrm{P}_{\mathrm{SG}}$ using intraoral pressure $\left(\mathrm{P}_{\mathrm{IO}}\right)$. They investigated different vocal modalities (breathy, modal, pressed, singing voices) (12), different intensities (13-15), or the impact of age and sex on the voice $(13,16,17)$. All the $\mathrm{P}_{\mathrm{IO}}$ values in the above-cited literature were below $1,8 \mathrm{kPa}$, including those corresponding to "loud voices". The use of real $\mathrm{P}_{\mathrm{SG}}$ allows continuous measurement, independently of the phonetic context. Previous work by our team demonstrated the utility of real $\mathrm{P}_{\mathrm{SG}}$ measures in obtaining a better understanding of glottal physiology during vocal rehabilitation exercises (18). To our knowledge, the $\mathrm{P}_{\mathrm{SG}}$ levels achieved in our study have not been previously investigated in the published 
literature. Snelleman and coll, who studied the estimated $\mathrm{P}_{\mathrm{SG}}$ (using intra-oesophageal pressure) in very loud speech over noise, described a maximum of $\mathrm{P}_{\mathrm{SG}}$ of $10 \mathrm{kPa}$ (19).

Relationships between $\mathrm{P}_{\mathrm{SG}}$ and voice SPL are proportional in most studies (13-17, 19). But the comparison of $P_{S G}$ (real or estimated) levels is a more direct way to assess the level of vocal effort rather than voice SPL. Voice SPL measurements vary depending on the square distance between the speaker and the microphone, and these data may not be directly compared from one study to another. In the present study, the intensity was measured with a distance of $90 \mathrm{~cm}$ from the mouth. Using the equation:

$$
\operatorname{SPL}\left(\mathrm{dB}_{\mathrm{SPL}}\right)=20 \log \left(\mathrm{d}_{2} / \mathrm{d}_{1}\right),
$$

the SPL values are $9.54 \mathrm{~dB}$ lower than SPL values that would have been measured with a distance of $30 \mathrm{~cm}$.

For the very high levels of $\mathrm{P}_{\mathrm{SG}}$ observed in our study, results showed a tendency for intensity to peak and then decrease while $\mathrm{P}_{\mathrm{SG}}$ continued to increase. Thus, the maximum $\mathrm{P}_{\mathrm{SG}}$ level did not correspond to maximum intensity level. This loss of proportionality was also observed in an experiment on excised animal larynges reported by Herbst (20), but the physiological origin of this observation remains unclear and Herbst found the opposite effect of the $\mathrm{P}_{\mathrm{SG}}$ on the voice SPL (see below).

\section{Non-periodic glottal behavior}

In normophonic conversational voice, non-periodic productions in the speech signal are unusual, although they appear in dysphonic voice and in some singing styles. Non-periodic laryngeal productions have been the focus of close investigation in neurological dysphonia (21). Jiang et al. (10) speculate that non-periodic behavior may occur in a normal larynx if subjected to excessive $\mathrm{P}_{\mathrm{SG}}$. In our study, non-periodic episodes were observed in the higher $\mathrm{P}_{\mathrm{SG}}$ values. This was also described by Herbst on excised animal larynges (20). However, non-periodic episodes do not necessarily correspond to maximum $\mathrm{P}_{\mathrm{SG}}$. Subject 3 produced an extremely high $\mathrm{P}_{\mathrm{SG}}$ in one shout $\left(\mathrm{P}_{\mathrm{SG}}>20 \mathrm{kPa}\right)$, while the EGG signal remained periodic. The very high value of $\mathrm{P}_{\mathrm{SG}}$ in this subject was not an artifact due to clogging or impingement on the tracheal wall because these accidents lead to a sudden fall in the $\mathrm{P}_{\mathrm{SG}}$ and never to a rise as happened 
here. Furthermore, pressures over $20 \mathrm{kPa}$ are not extra-physiological, they are frequently observed in trumpeters (22). It would appear possible, therefore, to control the larynx in order to maintain the periodicity of the glottal signal, even in the presence of extremely high $\mathrm{P}_{\mathrm{SG}}$. The transition from periodic to non-periodic signals is very abrupt, from one glottal cycle to the subsequent. This is an "ON-OFF" phenomenon and not a progressive deterioration of the signal until it becomes non-periodic, as would be expected if the $\mathrm{P}_{\mathrm{SG}}$ was solely responsible for the non-periodic productions. This bifurcation in laryngeal behavior is not associated with any break in the $\mathrm{P}_{\mathrm{SG}}$ curve, nor in that of voice SPL.

The physiological substratum of this bifurcation has to be determined. It could be due to the onset of vibration in the supra-glottal structures, especially the vestibular folds or the laryngeal surface of the epiglottis. Indeed, the vibration of the supra-glottal structures disturbs the acoustic signal with the onset of subharmonic frequencies and/or of non-periodic activity leading to a non-linear source-filter interaction (23). Another possible cause of the bifurcation could be some asymmetry in the two vocal folds--such as in tension, mass, or morphology (24). These hypotheses need further investigation.

Whether non-periodic vibration is more efficient as compared to periodic vibration is still unclear. Results reported by Herbst (20) on excised larynges from 2 female red deers showed a tendency for better efficiency with non-periodic productions, but the present results seem to contradict that finding. However, there are several possible explanations for this discrepancy including: the nature of the measures via excised larynges vs in vivo, possible interactions between the vocal tract and the larynx, differences between animal and human larynges, a low number of subjects in each study, and a lack of real glottis efficiency in the present study because of the lack of oral airflow values.

The decrease in intensity at very high pressure also needs further investigation. One hypothesis may be that the force driven by the $P_{S G}$ creates a sufficiently strong passive abduction of the vocal folds that their active (muscular) adduction may be limited and the amplitude of their vibration is reduced.

These questions should be clarified by future studies combining high-speed video recordings and measurements of the $\mathrm{P}_{\mathrm{SG}}$ with human larynges during in vivo and ex vivo shouts. 


\section{Limits of the study}

This is a preliminary study on an under-researched topic: the shouted voice, from aerodynamical, acoustical and electroglottographical point of views. Several limits were inherent to the methods used. The experiment had to take place in a medical environment, and the room could not be anechoic. This may introduce some noise in the acoustic data but the very high levels of intensity studied negate this issue. The synchronization of the acoustics and electroglottographic records was also systematically checked during the treatment of the data.

Only 3 persons participated in the experiment because of the quite invasive procedure of tracheal puncture. They were all men in order to preserve as far as possible the homogeneity of the study, but subject 1 was a trained singer, unlike the other two subjects, and this may have induced some differences in his vocal behavior (see fig. 1): he performed shouts with similar intensity to the others as the others, but with significantly lower $\mathrm{P}_{\mathrm{SG}}$.

Finally, the objective was to achieve the maximal voice SPL, despite already important equipment and the use of the mask for the oral airflow measure was not compatible with the freedom of the movements of the mouth.

\section{Conclusion}

The shouted voice is a very specific vocal mode. Glottal vibration may lose its periodicity when the larynx is submitted to very high levels of subglottal pressure. Determining the physiological origins of that phenomenon need further investigations.

\section{References}

1. Mittal VK, Yegnanarayana B. Effect of glottal dynamics in the production of shouted speech. J Acoust Soc Am 2013;133: 3050-61.

2. Dejonckere PH, Pépin F. Etude de l'effet Lombard par la mesure du niveau sonore équivalent. Folia Phoniatr 1983;35: 310-15.

3. Rothman HB1, Brown WS Jr, LaFond JR. Spectral changes due to performance environment in singers, nonsingers, and actors. J Voice 2002;16: 323-32. 
4. Garnier M, Bailly L, Dohen M, Welby P, Loevnbruck H. An acoustic and articulatory study of Lombard speech: global effects on the utterance. /Interspeech/ICSLP/, Pittsburgh(USA), 17-21 septembre 2006.

5. Ternström S, Bohman M, Södersten M. Loud speech over noise: some spectral attributes, with gender differences. J Acoust Soc Am 2006;119: 1648-65.

6. Stathopoulos ET, Sapienza C. Respiratory and laryngeal function of women and men during vocal intensity variation. J Speech Hear Res 1993;36: 64-75.

7. Lagier A, Vaugoyeau M, Ghio A, Legou T, Giovanni A, Assaiante C. Coordination between posture and phonation in vocal effort behavior. Folia Phoniatr Logop 2010;62: 195202.

8. Sundberg J, Fahlstedt E, Morell A. Effects on the glottal voice source of vocal loudness variation in untrained female and male voices. J Acoust Soc Am 2005;117: 879-85.

9. Winholtz WS, Titze IR. Conversion of a head-mounted microphone signal into calibrated SPL units. J Voice 1997;11: 417-21.

10. Jiang JJ, Zhang Y, McGilligan C. Chaos in voice, from modeling to measurement. J Voice 2006;20: 2-17.

11. Baken RJ, Orlikoff RF. Clinical measurement of speech and voice. San Diego: Singular Publishing Group, 2000.

12. Akerlund L, Gramming P. Average loudness level, mean fundamental frequency, and subglottal pressure: comparison between female singers and nonsingers. J Voice 1994;8:26370 .

13. Tang J, Stathopoulos ET. Vocal efficiency as a function of vocal intensity: a study of children, women, and men. J Acoust Soc Am 1995;97: 1885-92.

14. Holmberg EB, Hillman RE, Perkell JS. Glottal airflow and transglottal air pressure measurements for male and female speakers in soft, normal, and loud voice. J Acoust Soc Am 1988;84: 511-29.

15. Gramming P, Sundberg J, Ternström S, Leanderson R, Perkins WH. Relationship between changes in voice pitch and loudness. J Voice 1988;2: 118-26.

16. McAllister A, Sundberg J. Data on subglottal pressure and SPL at varied vocal loudness and pitch in 8- to 11-year-old children. J Voice 1998;12: 166-74.

17. Stathopoulos ET. Relationship between intraoral air pressure and vocal intensity in children and adults. J Speech Hear Res 1986;29: 71-4.

18. Robieux C, Galant C, Lagier A, Legou T, Giovanni A. Direct measurement of pressures involved in vocal exercises using semi-occluded vocal tracts. Logoped Phoniatr Vocol. 2014,1-7. (Epub ahead of print) (doi:10.3109/14015439.2014.902496). 
19. Snelleman J, Versnel H and Dejonckere P,Loud phonation: subglottal pressures and Closed Quotients. PEVOC 2007

20. Herbst C. T. Glottal efficiency of periodic and irregular in vitro red deer voice production. Acta Acoustica united with Acoustica 2014, 100: 724-33

21. Hertrich I, Lutzenberger W, Spieker S, Ackermann H. Fractal dimension of sustained vowel productions in neurological dysphonias: an acoustic and electroglottographic analysis. J Acoust Soc Am 1997;102: 652-4.

22. Fletcher NH, Tarnopolsky A. Blowing pressure, power, and spectrum in trumpet playing. J Acoust Soc Am. 1999;105:874-81

23. Bailly L, Bernardoni NH, Müller F, Rohlfs AK, Hess M. Ventricular-fold dynamics in human phonation. J Speech Lang Hear Res 2014;57: 1219-42.

24. Giovanni A, Ouaknine M, Guelfucci R, Yu T, Zanaret M, Triglia JM. Nonlinear behavior of vocal fold vibration: the role of coupling between the vocal folds. J Voice. 1999;13: 46576. 
Table I: voice SPL, $\mathrm{P}_{\mathrm{SG}}$, and EGG analysis for each shout. The following data are presented: for the entire shout: duration of the shout, segmentation of the shout depending on EGG classification (periodic, non-periodic); and for each EGG type: relative duration of the segment (as a percentage of the overall shout duration), mean $\mathrm{P}_{\mathrm{SG}}$, mean voice SPL, ratio of mean voice $S P L / m e a n P_{S G}$, ratio of voice $S P L / P_{S G}$ at $P_{S G} \max$.

\begin{tabular}{|c|c|c|c|c|c|c|c|c|c|}
\hline $\begin{array}{l}\text { Subject- } \\
\text { Trial }\end{array}$ & $\begin{array}{l}\text { Duration } \\
\text { of the } \\
\text { whole } \\
\text { shout } \\
\text { (ms) }\end{array}$ & $\begin{array}{l}\text { EGG } \\
\text { Classification }\end{array}$ & $\begin{array}{l}\text { Duration } \\
\text { of the } \\
\text { segment } \\
\text { (\% of } \\
\text { the } \\
\text { whole } \\
\text { shout) }\end{array}$ & $\begin{array}{l}\text { Mean } \\
\mathrm{P}_{\mathrm{SG}} \\
(\mathrm{kPa})\end{array}$ & $\begin{array}{l}\text { Maximal } \\
\mathrm{P}_{\mathrm{SG}} \\
(\mathrm{kPa})\end{array}$ & $\begin{array}{l}\text { Mean } \\
\text { voice } \\
\text { SPL } \\
\text { (dB } \\
\text { SPL) }\end{array}$ & $\begin{array}{l}\text { Voice } \\
\text { SPL (dB } \\
\text { SPL)for } \\
\text { maximal } \\
P_{S G}\end{array}$ & $\begin{array}{l}\text { Mean } \\
\text { voice } \\
\text { SPL/ } \\
\text { mean } \\
\mathrm{P}_{\mathrm{SG}}\end{array}$ & $\begin{array}{l}\text { Voice } \\
\text { SPL/P } \\
\text { at } P_{S G} \\
\max \end{array}$ \\
\hline $1-1$ & 1541 & Periodic & 100 & 4.62 & 4.932 & 102,73 & 100.37 & 22.0 & 20.3 \\
\hline \multirow[t]{2}{*}{$1-2$} & \multirow[t]{2}{*}{1627} & Periodic & 32,14 & 2.298 & 3.176 & 99,74 & 100.32 & 43.4 & 31.6 \\
\hline & & Non-periodic & 67,86 & 4.565 & 5.462 & 100,67 & 98.09 & 22.0 & 17.9 \\
\hline $1-3$ & 1669 & Periodic & 100 & 3.038 & 4.656 & 101,68 & 100.09 & 33.4 & 21.5 \\
\hline \multirow[t]{2}{*}{$1-4$} & \multirow[t]{2}{*}{1622} & Periodic & 36,30 & 2.699 & 5.177 & 95,62 & 99.96 & 35.4 & 19.3 \\
\hline & & Non-periodic & 63,70 & 4.292 & 5.178 & 97,80 & 97.35 & 22.8 & 18.8 \\
\hline $1-5$ & 1606 & Periodic & 100 & 2.992 & 4.145 & 100,60 & 102.42 & 33.6 & 24.7 \\
\hline \multirow[t]{2}{*}{$1-6$} & \multirow[t]{2}{*}{1697} & Periodic & 20,68 & $0.419 *$ & 5.750 & 91,38 & 99.93 & 218 & 17.4 \\
\hline & & Non-periodic & 79,32 & 4.462 & 5.762 & 99,60 & 99.05 & 22.3 & 17.2 \\
\hline \multirow[t]{2}{*}{$2-1$} & \multirow[t]{2}{*}{1736} & Periodic & 35,14 & 8.684 & 13.070 & 103,26 & 108.93 & 11.9 & 8.3 \\
\hline & & Non-periodic & 64,86 & 11.39 & 12.638 & 107,10 & 108.23 & 9.4 & 8.5 \\
\hline \multirow[t]{2}{*}{$2-2$} & \multirow[t]{2}{*}{1625} & Periodic & 25,85 & 7.004 & 12.067 & 100,93 & 108.81 & 14.4 & 9.0 \\
\hline & & Non-periodic & 74,15 & 10.00 & 12.089 & 105,6 & 109.43 & 10.5 & 9.0 \\
\hline $3-1$ & 525 & Periodic & 100 & 6.388 & 9.851 & 98,03 & 105.58 & 15.3 & 10.7 \\
\hline $3-2$ & 696 & Periodic & 100 & 6.928 & 9.373 & 101,02 & 102.25 & 14.6 & 10.9 \\
\hline $3-3$ & 652 & Periodic & 100 & 6.981 & 9.623 & 100,04 & 104.69 & 14.3 & 10.9 \\
\hline $3-4$ & 874 & Periodic & 100 & $>20$ & $>20$ & 105,16 & 111.20 & $<5.2$ & $<5.5$ \\
\hline
\end{tabular}

* This $\mathrm{P}_{\mathrm{SG}}$ value may appear confusing. It is very low because the subject only produced type 1 EGG in a very short initiation of a shout and rapidly switched to types 2 and 3 . 


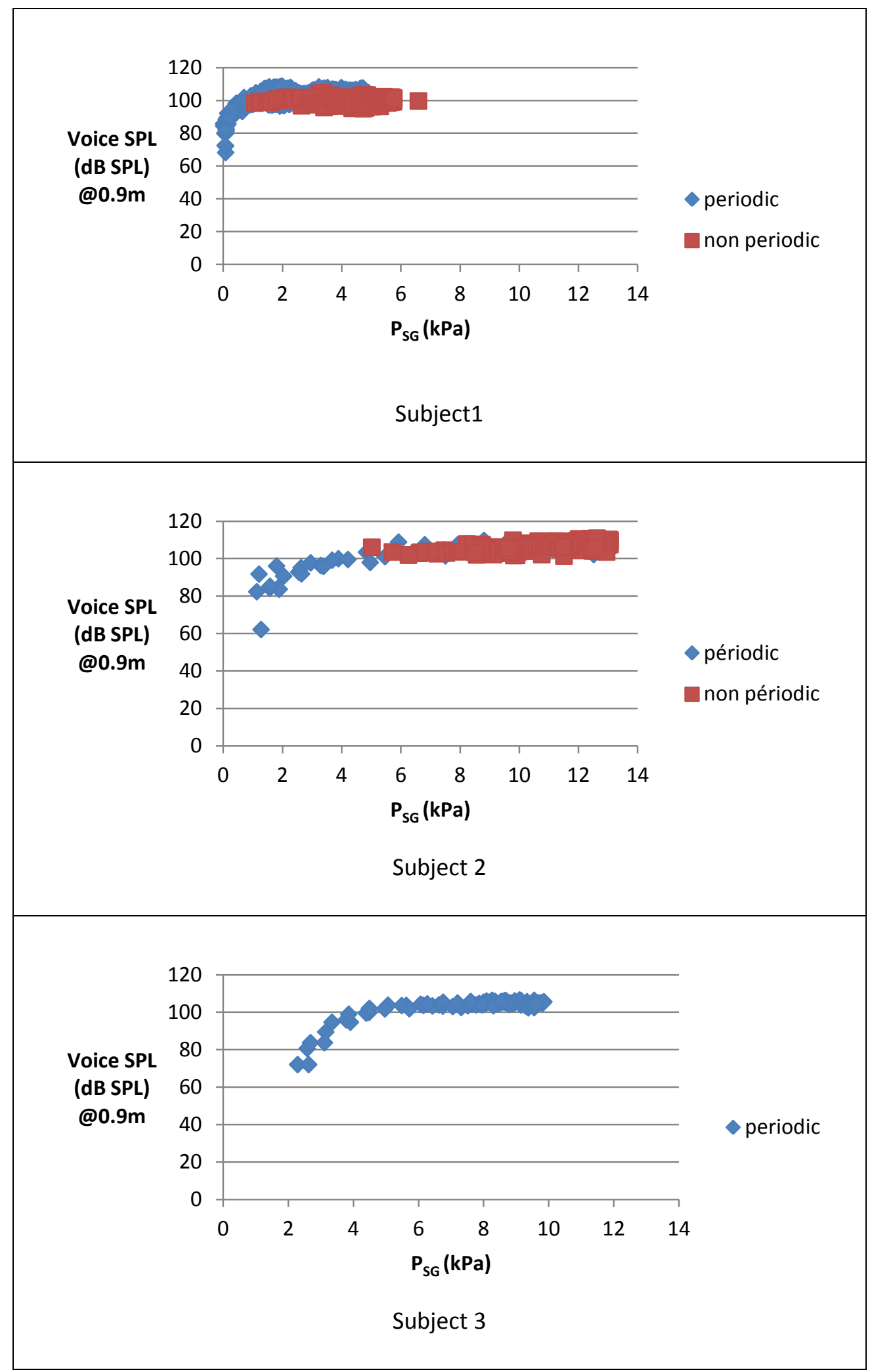

Figure 1: Voice SPL of shouted productions as a function of subglottal pressure. 


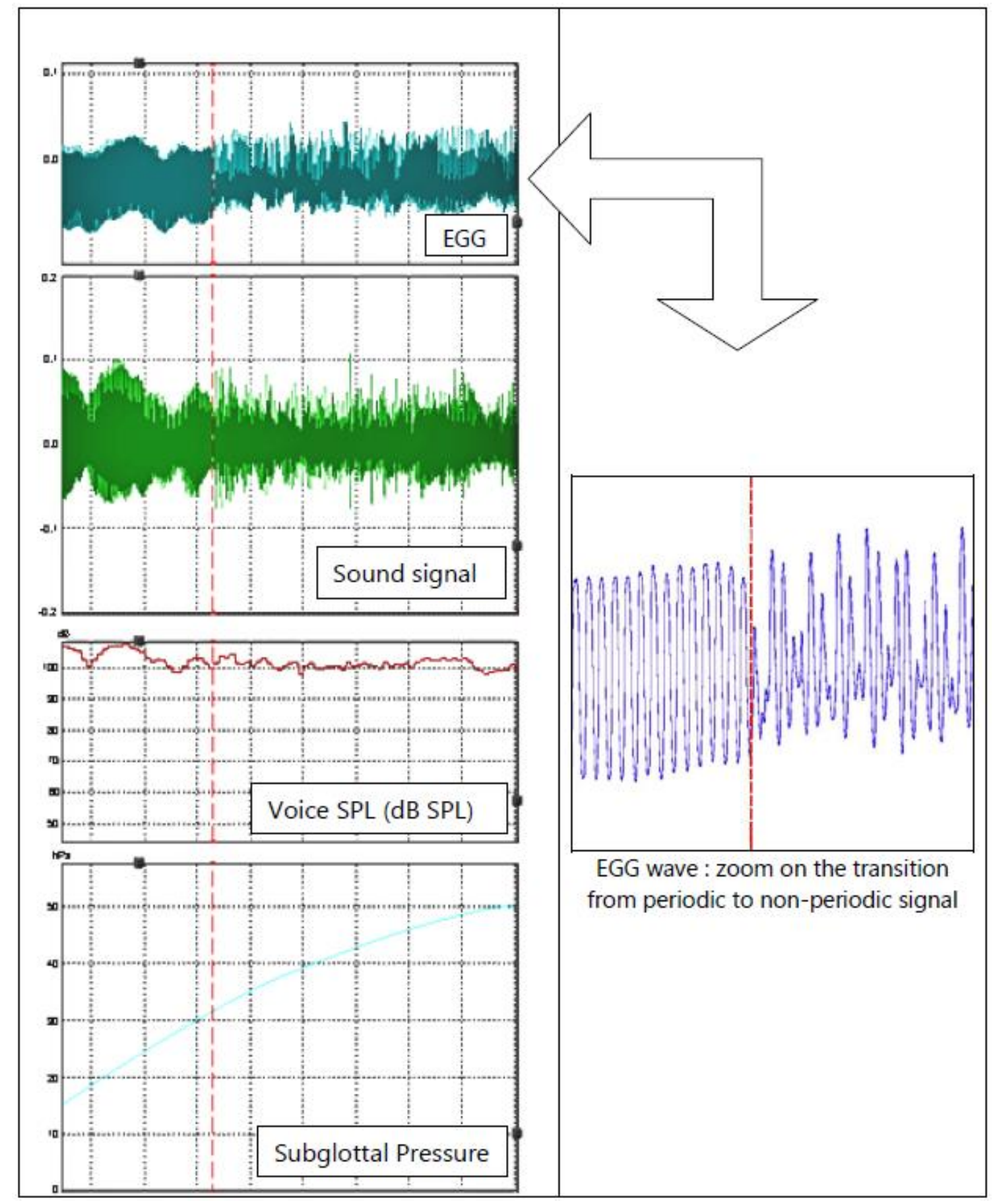

Figure 2: Analysis of the transition from a periodic glottal signal to a non-periodic glottal signal. 